\title{
A NOVEL TECHNIQUE FOR TESTING OSTEOINTEGRATION IN LOAD-BEARING CONDITIONS
}

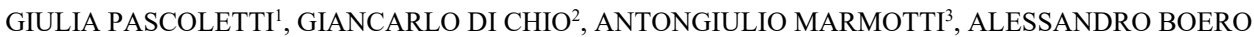 \\ BARONCELLI $^{4}$, PIERO COSTA ${ }^{5}$, ANDREA TANCREDI LUGAS ${ }^{2} \&$ GIANPAOLO SERINO $^{2}$ \\ ${ }^{1}$ Department of Industrial and Mechanical Engineering, University of Perugia, Italy \\ ${ }^{2}$ Department of Mechanical and Aerospace Engineering, Politecnico di Torino, Italy \\ ${ }^{3}$ University Hospital St. Luigi Gonzaga, University of Torino, Italy \\ ${ }^{4}$ Department of Animal Pathology, University of Torino, Italy \\ ${ }^{5}$ Intrauma S.r.1., Rivoli, Italy
}

\begin{abstract}
When a new material for the realization of an implantable device in the bone is being studied, in addition to its chemical-physical-mechanical characterization, tests regarding osteointegration are performed. Usually, researchers evaluate the ability of biomaterials to bind to the bone under load-bearing conditions, through animal experiments in the phase of a preclinical study, provided the respective authorization by the ethics committee. In more detail, plugs made of the material under investigation are prepared and implanted into a weight-bearing portion of the skeleton of animals (typically into the knee joint of goats, pigs, rabbits or dogs); after a pre-set time, the animal is sacrificed, the bone element is extracted, it is tested mechanically - generally by means of a pull-out test - and finally it is examined histologically. Mechanical tests often require demanding specimen preparation, which could bias results. In the scope of a research regarding the interface behaviour of a ceramic plug (two different ceramic plugs) compared to a titanium one, the authors have suggested a novel testing technique which allows to perform 'push-in' tests, instead of the more common pull-out tests. This methodology has been followed here to compare titanium versus ceramic plugs at different times from implant $(0,3$ months, 1 year) into goat knees. As a result, the study reports the shear resistance of bone-plug interfaces. The statistical analysis of the data allowed us to establish that titanium plugs systematically exhibit a higher resistance $(p<0.10)$; this resistance undergoes a significant increment as time passes $(p<0.07)$ due to progressive osteointegration.
\end{abstract}

Keywords: mechanical test, bone-biomaterial interface, osteointegration.

\section{INTRODUCTION}

When a new material for the realization of an implantable device is being investigated, first of all chemical-physical tests are performed, then biocompatibility is tested, and eventually, according to its destination (for example in the case of prostheses or bone synthesis devices), its bioactivity is tested. The osteointegration of an implantable device depends on its constitutive material and on surface properties. Bone remodelling, i.e. the structural reorganization of the bone not only at the interface but all around the device, depends above all on the state of strain and stress that the device induces into the bone when it is implanted.

The knowledge of the mechanical properties of the bone tissue and of the structural behaviour of the whole native bone both in physiological and pathological conditions is mandatory in order to identify main specifications for restorative materials, and to assess if and how the bone can be interfaced with other materials and devices.

The structural analysis of skeletal body elements and of biomechanical systems consisting of a bone element coupled to a prosthesis, an implant or a fracture synthesis device, can be performed both numerically and experimentally [1]. There are many examples of clinical problems which have moved from a qualitative assessment to a quantitative evaluation thanks to the respective modelling [2]-[9] or to the application of classical experimental methods of structural analysis to the evaluation of the efficacy of procedures or surgical techniques [10]- 
[18] or to the evaluation of the mechanical characteristics of the materials used at different scales of investigation [19]-[24].

However, each approach has its own limitations: numerical models can be very complex and consequently need to be validated; experimental tests cannot faithfully reproduce the real conditions and they require simplifications, in most cases. On the basis of these assumptions, both approaches still remain necessary and in most cases complementary.

Preclinical studies can be performed as a validation of both in vitro tests and numerical models. Here researchers usually focus their attention on the ability of prosthetic materials to bind to the bone under load-bearing conditions, and resort to animal experiments. Synthetic plugs are implanted into the weight-bearing portion of the femoral condyles of animals (typically goats, pigs, rabbits or dogs); and the animals are sacrificed after a pre-set time, bone portions are tested mechanically and examined histologically.

Mechanical testing often requires demanding specimen preparation which could bias results: first of all bone cubes must be cut from the whole bone [25] (Fig. 1(a)); secondly, the plugs must bear an attachment area (like a transversal hole [26] or an axial threaded hole [27], Fig. 1(b)) that is not easily accessible; third, the mechanical attachment to the plugs for pull-out tests requires milling adjacent bone (in the transversal hole case), or the removal of ingrowth bone (in the case depicted in Fig. 1(b)).

A novel technique is here introduced, which allows to perform 'push-in' tests after performing two easy operations which do not affect the condylar area: planar cutting of the whole bone and end milling of an axial hole.

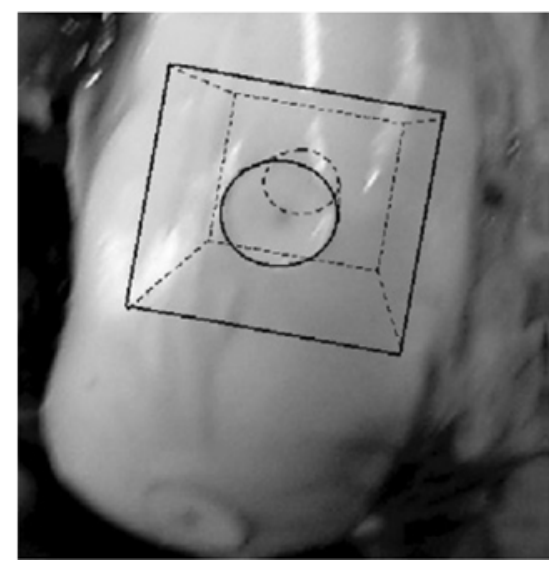

(a)

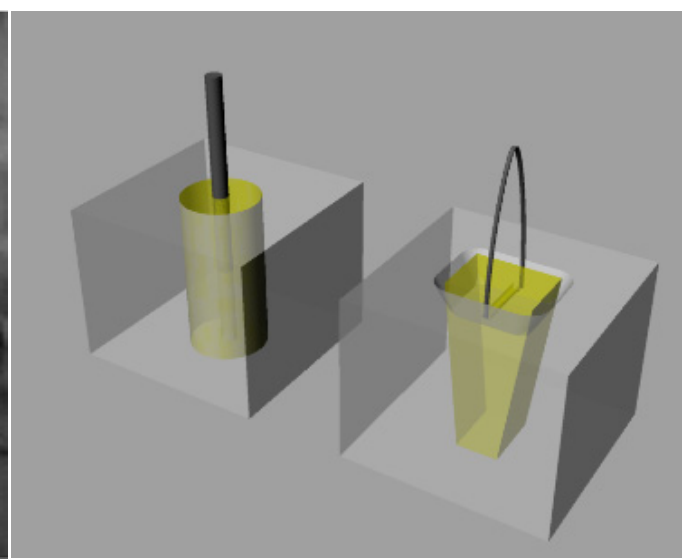

(b)

Figure 1: Specimen preparation for pull-out tests. (a) Bone cube cutting [25]; (b) Types of attachment to the specimen.

\section{MATERIALS AND METHODS}

The right knees of eighteen adult Roccaverano goats were implanted with two types of ceramic plugs, $\mathrm{Al}_{2} \mathrm{O}_{3} / \mathrm{ZrO}_{2}$ nanocomposites, produced starting from high purity powders, with different ratios among the components, respectively alumina toughened zirconia (16 $\mathrm{wt} \% \mathrm{Al}_{2} \mathrm{O}_{3}, 84 \mathrm{wt} \% \mathrm{ZrO}_{2}$ ) surface treated with phosphoric acid in hydrothermal conditions and zirconia toughened alumina $\left(20 \mathrm{wt} \% \mathrm{ZrO}_{2}, 80 \% \mathrm{Al}_{2} \mathrm{O}_{3}\right)$ coated on the surface with bioglass and a titanium plug $\left(\mathrm{Ti}_{6} \mathrm{Al}_{4} \mathrm{~V}\right.$, sandblasted with corundum on the surface) on the two 
condyles (Fig. 2(a)). The plugs were rectangular cuboids ( $8 \mathrm{~mm} \times 4 \mathrm{~mm} \times 8 \mathrm{~mm}$, Fig. 2(b)). Experiments on animals were authorized by the Ethical Committee of Animal Care and Use Center (CISRA, Faculty of Veterinary Medicine, University of Torino, Grugliasco, Italy).

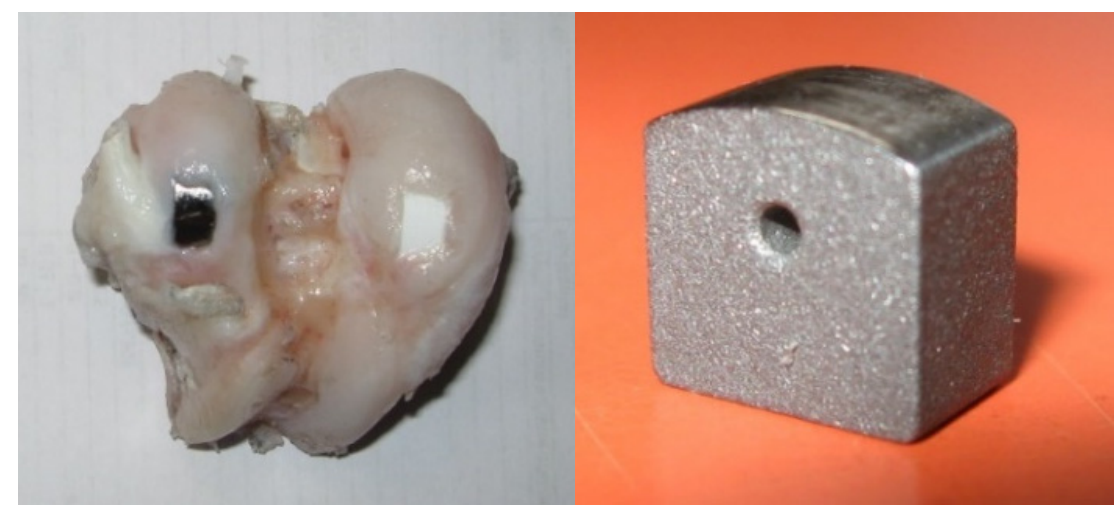

(a)

(b)

Figure 2: "Push-in" test. (a): Initial specimen; (b) Example of titanium plug.

Goats were sacrificed respectively 3 months and 1 year following the implantation and the contralateral knee has been implanted with the same plugs, to be used as a reference (time zero). Following excision, bone specimens underwent histological and mechanical tests; the second ones are considered in this work. The authors set up a novel technique for the experimental evaluation of osteointegration, through the measurement of the maximum load withstood by the plug before starting to slide in the housing. This evaluation is revealing the shear stress which the interface can withstand.

The procedure suggested is the following:

- $\quad$ first of all, the femur bones are excised;

- a planar cut is performed, perpendicularly to the axis of the plug;

- a hole is drilled on the distal side: this hole and the plug should be coaxial, the hole should be larger than the plug, and its depth should be such as to contact the bottom of the plug (Fig. 3(a));

- the bone specimen is placed inside a grasp designed so as to receive and block the knees whose shape, might be slightly different from one another (Fig. 3(b));

- a "push-in" test is performed moving the machine crosshead downward (MTS QTest-10 Testing System), at a speed of $2 \mathrm{~mm} / \mathrm{min}$ (Fig. 3(c));

- a punctual compression test is performed on intact bone to determine the quality of the surrounding trabecular and cortical bone;

- the whole curve of force versus displacement is recorded.

In "push-in" tests, force/displacement curves were analysed in order to establish the maximum load withstood and to evaluate the ultimate interface shear stress as the peak force divided by the lateral surface of the plug.

In bone compression tests (Fig. 4), the initial linear portion of the force/displacement curves [1] was used to assess bone quality since it is related to bone's Young modulus, according to Timoshenko and Goodier's equation [28]. 


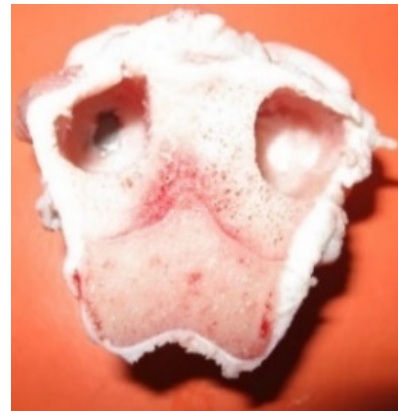

(a)

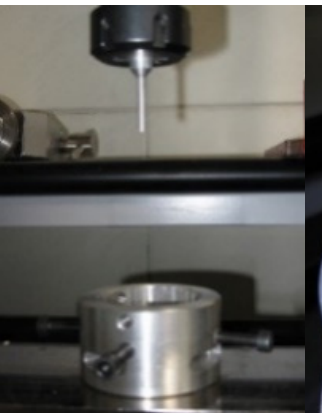

(b)

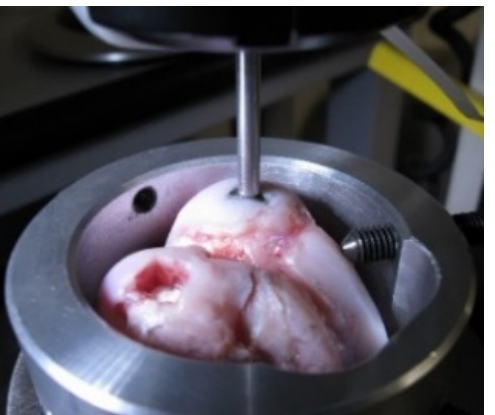

(c)

Figure 3: Suggested procedure. (a) Drilled specimen; (b) Gripping and loading system; (c) 'Push-in' test.

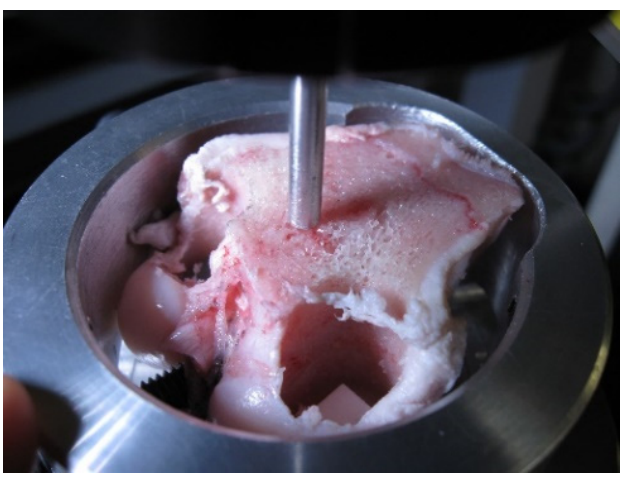

(a)

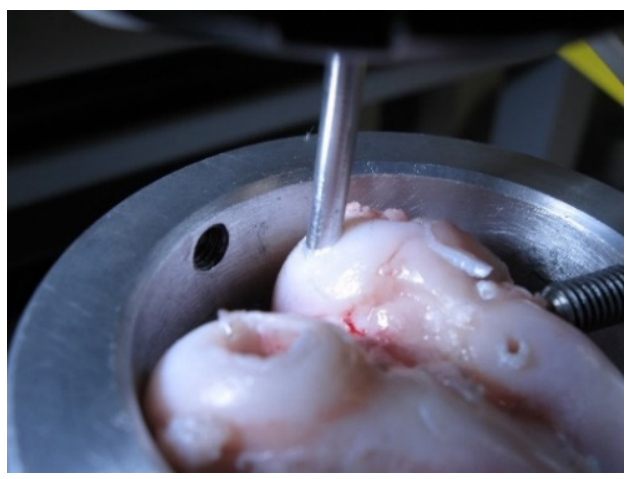

(b)

Figure 4: Compression tests. (a) Trabecular bone; (b) Cortical bone.

\section{RESULTS AND DISCUSSION}

Bone compression tests results showed a high variance of stiffness both for cortical and trabecular bone (Fig. 5) and no significant differences between bone quality at 0 months, 3 months and 1 year have resulted.

Fig. 6 shows an example of force/displacement curves obtained during "push-in" tests on ceramic plugs at time zero. The test performed on the two types of ceramic plugs were put together because their behaviour was quite the same. In Fig. 7 the mean values of the peak loads recorded in the push-in test are shown, with the respective standard deviation, both for ceramic and titanium plugs, at different times from implant.

The statistical analysis of data (two-way ANOVA) allowed to establish that titanium plugs systematically exhibit a higher resistance $(p<0.10)$; they osteointegrate and therefore the shear resistance undergoes a significant increment with time $(p<0.07)$. The difference between titanium and ceramic plugs does not vary significantly at different times from implant. 


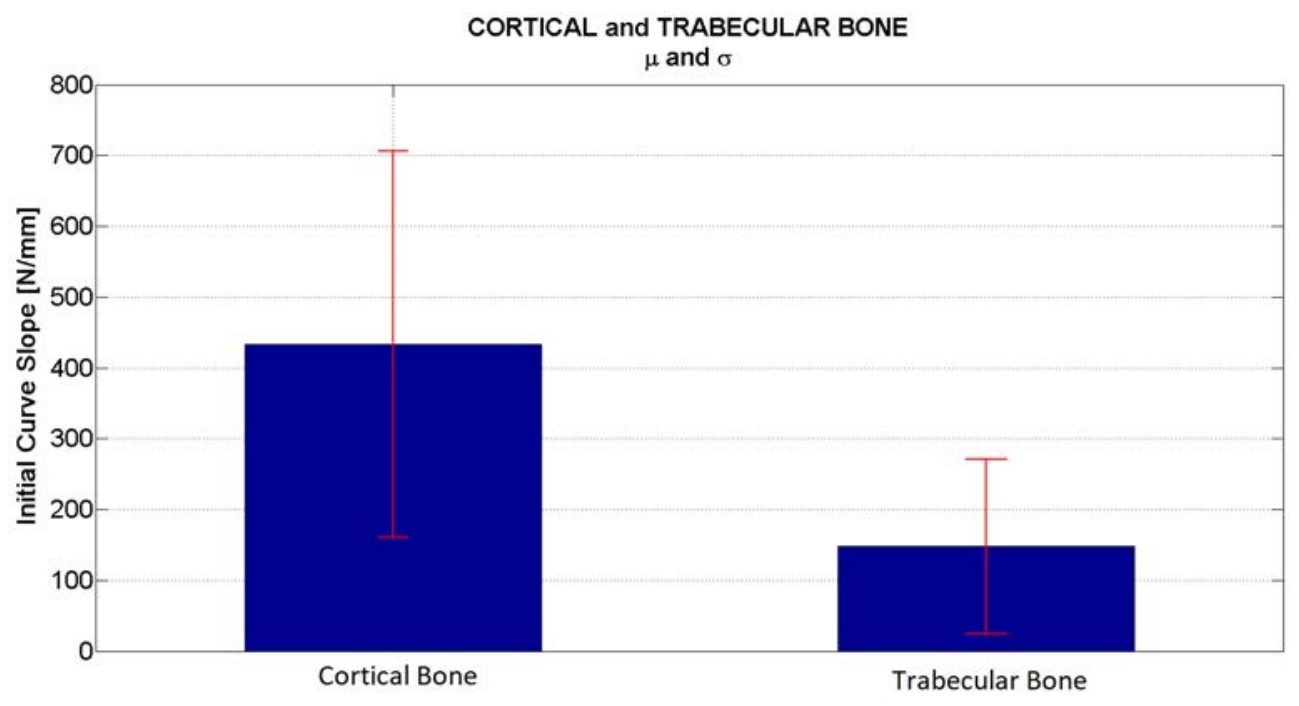

Figure 5: Mean values $\mu$ and standard deviation $\pm \sigma$ of cortical bone and trabecular bone stiffness.

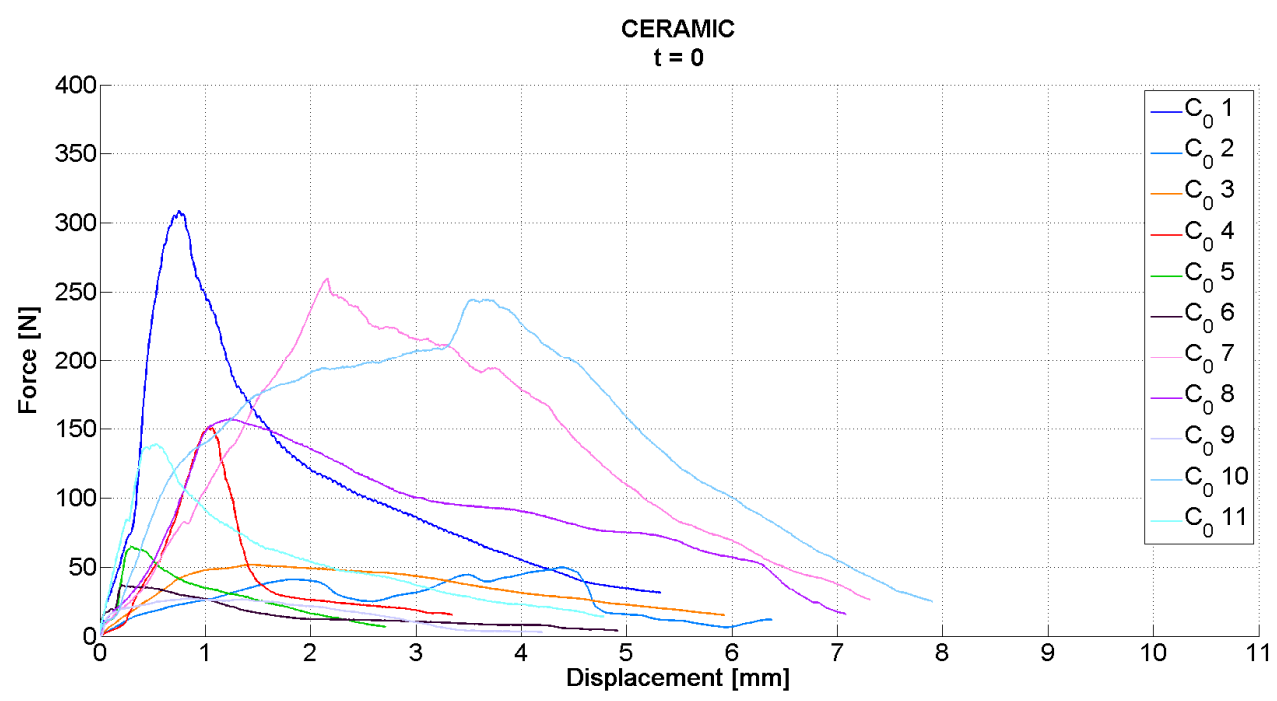

Figure 6: Force/displacement curves obtained during "push-in" tests on ceramic plugs at time zero.

The evaluation of ultimate interface shear stress resulted to range from $0.71 \pm 0.52 \mathrm{MPa}$ (time zero, ceramic plug) to $3.05 \pm 0.54 \mathrm{MPa}$ (1 year, titanium plug); Suzuki et al. [26] found higher values on goats: $4.43 \pm 0.45 \mathrm{MPa}$, however they used tapered implants; an ultimate shear stress equal to $0.62 \mathrm{MPa}$ can be derived from Whiteside et al. [25], on cylindrically shaped implants, at time zero, on pigs. 


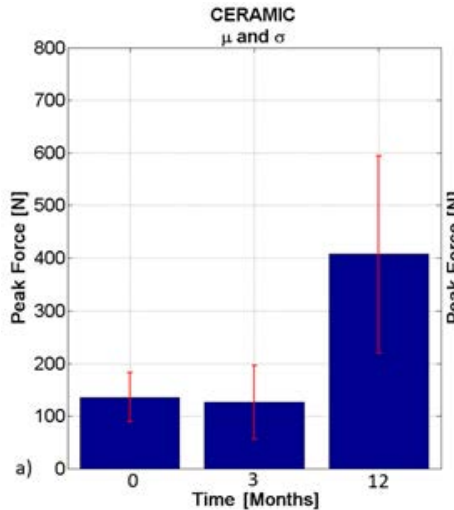

(a)

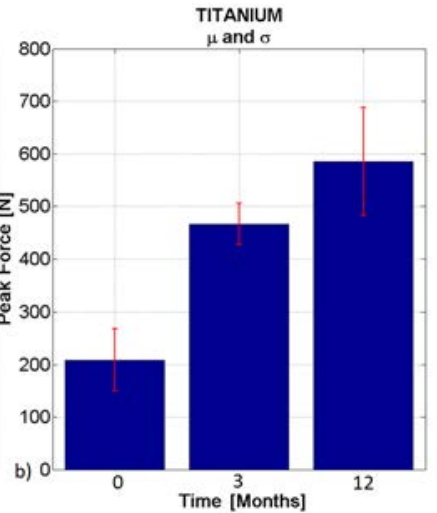

(b)

Figure 7: Mean values $\mu$ and standard deviation $\pm \sigma$ of peak loads recorded in the push-in, respectively, at the different times from implant. (a) Ceramic; (b) Titanium plug.

From the histological point of view, the titanium plugs proved to be more stable and at 3 months and 1 year than the ceramic ones, in fact they achieved greater peripheral osteointegration; ceramic plugs, on the other hand, were surrounded by a fibrous reaction and only few areas of new bone apposition.

\section{CONCLUSIONS}

The test has resulted to be sensitive to the plug constitutive material and the time passed since the implantation. Tests allowed to establish that the end milled hole should overpass the maximum plug dimension by at least $2 \mathrm{~mm}$ in order to avoid secondary impingement of the bone plug against bone walls.

\section{REFERENCES}

[1] Zanetti, E.M. \& Bignardi, C., Structural analysis of skeletal body elements: numerical and experimental methods. Biomechanical systems technology, ed. by C.T. Leondes, World Scientific Publishing: University of California, Los Angeles, vol. 3, pp. 185225, 2009.

[2] Vitale, M.C., Chiesa, M., Coltellaro, F., Bignardi, C., Celozzi, M. \& Poggio, C., FEM analysis of different dental root canal-post systems in young permanent teeth. European Journal of Paediatric Dentistry, 9(3), pp. 111-117, 2008.

[3] Zanetti, E.M. \& Bignardi, C., Mock-up in hip arthroplasty pre-operative planning. Acta of Bioengineering and Biomechanics, 15(3), pp 123-128, 2013.

[4] Zanetti, E.M. et al., A structural numerical model for the optimization of double pelvic osteotomy in the early. Veterinary and Comparative Orthopaedics Traumatology, 3(4), pp. 256-264, 2017.

[5] Calì, M. et al., Influence of thread shape and inclination on the biomechanical behaviour of plateau implant systems. Dental Materials, 34(3), pp. 460-469, 2018.

[6] Zanetti, E.M., Bignardi, C., Terzini, M., Putame, G. \& Audenino, A.L., A multibody model for the optimization of hip arthroplasty in relation to range of movement. Academy of Management Journal, 11(10), pp. 486-491, 2018.

[7] Putzer, D., Nogler, M., Terzini, M., Mannara, R. \& Bignardi, C., A finite element analysis for a new short stem concept design with spherical bone interface for hip 
resurfacing. International Journal of Mechanical Engineering and Technology, 9(3), pp. 923-935, 2018.

[8] Aldieri, A. et al., Osteoporotic hip fracture prediction: is T-score based criterion enough? A Hip Structural Analysis based model. Journal of Biomechanical Engineering, 140(11), 2018.

[9] Terzini, M. et al., Multibody modelling of ligamentous and bony stabilizers in the human elbow. Muscles, Ligaments and Tendons Journal, 7(4), pp. 493-502, 2018.

[10] Bresciano, M., Schierano, G., Manzella, C., Screti, A., Bignardi, C. \& Preti, G., Retention of luting agents on implant abutments of different height and taper. Clinical Oral Implant Research, 16, pp. 594-598, 2005.

[11] Menicucci, G., Ceruti, P., Barabino, E., Screti, A., Bignardi, C. \& Preti G., A preliminary in vivo trial of load transfer in mandibular implant-retained overdentures anchored in 2 different ways: allowing and counteracting free rotation. International Journal of Prosthodontics, 19(6), pp. 574-576, 2006.

[12] Zanetti, E.M. \& Audenino, A.L., Differential thermography for experimental, full-field stress analysis of hip arthroplasty. Journal of Mechanics in Medicine and Biology, 10(3), pp. 515-529, 2010.

[13] Zanetti, E.M., Bignardi, C. \& Audenino, A.L., Human pelvis loading rig for static and dynamic stress analysis. Acta of Bioengineering and Biomechanics, 14(2), pp. 61-66, 2012.

[14] Boero Baroncelli, A., Reif, U., Bignardi, C. \& Peirone, B., Effect of screw insertion torque on push-out and cantilever bending properties of five different angle-stable systems. Veterinary Surgery, 42(3), pp. 308-315, 2013.

[15] Manzella, C., Burello, V., Bignardi, C., Carossa, S. \& Schierano, G., A method to improve passive fit of frameworks on implant-supported prostheses: An in vivo study. International Journal of Prosthodontics, 26(6), pp 577-579, 2013.

[16] Manzella, C., Bignardi, C., Burello, V., Carossa, S. \& Schierano, G., Method to improve passive fit of frameworks on implant-supported prostheses: An in vitro study. Journal of Prosthetic Dentistry, 116(1), pp. 52-58, 2016.

[17] Zanetti, E.M., Pascoletti, G., Calì, M., Bignardi, C. \& Franceschini, G., Clinical Assessment of dental implant stability during follow-up: What is actually measured, and perspectives. Biosensors (Basel), 8(3), p. E68, 2018.

[18] Bignardi, C., Zanetti, E.M., Terzini, M., Ciccola, A.R., Schierano, G. \& Audenino, A.L., Reliability, learnability and efficiency of two tools for cement crowns retrieval in dentistry. The Open Biomedical Engineering Journal, 12(1), pp. 27-35, 2018.

[19] Peluccio, M.S., Bignardi, C., Lombardo, S., Montevecchi, F.M. \& Carossa, S., Comparative study of nanomechanical properties of cements used in teeth restoration. Journal of Physics: Condensed Matter, 19, p. 395003, 2007.

[20] Bignardi, C., Petraroli, M. \& Pugno, N.M., Nanoindentation on conch shells of gastropoda and bivalvia molluscs reveal anisotropic evolution against external attacks. Journal of Nanoscience and Nanotechnology, 10(10), pp. 6453-6460, 2010.

[21] Zanetti, E.M., Perrini, M., Bignardi, C. \& Audenino, A.L., Bladder tissue passive response to monotonic and cyclic loading. Biorheology, 49(1), pp. 49-63, 2012.

[22] Terzini, M., Bignardi, C., Castagnoli, C., Cambieri, I., Zanetti, E.M. \& Audenino, A.L., Ex vivo dermis mechanical behavior in relation to decellularization treatment length. The Open Biomedical Engineering Journal, 10, pp. 34-42, 2016.

[23] Terzini, M., Bignardi, C., Castagnoli, C., Cambieri, I., Zanetti, E.M. \& Audenino, A.L., Dermis mechanical behaviour after different cell removal treatments. Medical Engineering \& Physics, 38(9), pp. 862-869, 2016. 
[24] Aldieri, A., Terzini, M., Bignardi, C., Zanetti E.M. \& Audenino A.L., Implementation and validation of constitutive relations for human dermis mechanical response. Medical \& Biological Engineering \& Computing, 56(11), pp. 2083-2093, 2018.

[25] Whiteside, R.A., Bryant, J.T., Jakob, R.P., Mainil-Varlet, P. \& Wyss, U.P., Short-term load bearing capacity of osteochondral autografts implanted by the mosaicplasty technique: An in vitro porcine model. Journal of Biomechanics, 36(8), pp. 1203-1208, 2003.

[26] Suzuki, T., Fujibayashi, S., Nakagawa, Y., Noda, I. \& Nakamura, T., Ability of zirconia double coated with titanium and hydroxyapatite to bond to bone under loadbearing conditions. Biomaterials, 27(7), pp. 996-1002, 2006.

[27] Aebli, N. et al., In vivo comparison of the osseointegration of vacuum plasma sprayed titanium- and hydroxyapatite-coated implants. Journal of Biomedical Materials Research A, 66(2), pp. 356-363, 2003.

[28] Timoshenko, S.P. \& Goodier, J.N., Theory of Elasticity, New York: McGraw-Hill, 1970. 